\title{
A RETROSPECTIVE STUDY ON OCCURRENCE OF MYIASIS IN RUMINANTS
}

\author{
N. S. Juyena ${ }^{* *}$, M. A. H. Tapon R. N. Ferdousy S. Paul and M. M. Alam \\ Department of Surgery and Obstetrics, Bangladesh Agricultural University \\ Mymensingh-2202, Bangladesh
}

\begin{abstract}
The myiasis is very common surgical affections of ruminants in Bangladesh. There are limited researches on the maggot wound infestation in Bangladesh. A retrospective study was performed to collect data and to get a clear and genuine concept on myiasis affections in ruminants in respect to species. age, sex, breed, season and predilection sites. The present study was conducted in Veterinary Clinic, Bangladesh Agricultural University, Mymensingh and data was recorded from 2008 to 2012. Results showed that 151 animals were affected with myiasis and maggot wounds predominantly occurred in the cattle $(71.6 \%)$ among which calves were more affected. Myiasis was very prone to occur in the navel, vulva, leg and ear. During the study period, more affection occurred in animals of below 6 months $(41 \%)$. The females $(66 \%)$ were more frequently affected than the males $(34 \%)$ and cross breed (57\%) was more affected compared to local breed (43\%).Moreover, infestation frequently observed from March to June $(80 \%)$. This study could help veterinarians as well as farmers to be aware of the occurrence of maggot wounds and to implement protective measures with minimum complications.
\end{abstract}

Key Words: Retrospective study, Myiasis, Ruminants

\section{INTRODUCTION}

Myiasis results from the invasion of tissues or organs of man and animals by dipterous larvae which feed on the host's live/dead tissues and body fluids (Zumpt, 1965). Myiasis in domestic animals is a worldwide problem causing huge economic losses in livestock through reduced productivity and tissue damage (Chhabra and Pathak, 2009). Wounds, ulcers, sores, broken horn, injured eyes and sometimes soiled hair attract myiasis-causing flies to infest domestic animals. When an injury on an animal ensuing foul smell attracts gravid female flies to oviposit on the edge of the wound, the hatched larvae burrow deep into the necrotic or living tissues of the host. Larvae are usually associated with skin wounds of any domestic animal that have become contaminated with bacteria or with a matted hair coat contaminated with feces (Obanda et al., 2013). Myiasis is not lethal to the

\footnotetext{
${ }^{1}$ Associate Professor, Department of Surgery and Obstetrics, Bangladesh Agricultural University Mymensingh-2202, Bangladesh

*Corresponding author (Email: juyenahabib@yahoo.com)
} 
animal. Untreated maggot wounds may result in result in death of the animal, depending on the size and condition of the animal, the location of the infestation, and whether there are other complications such as infection or toxicity. This condition may cause abortion, reduced milk, meat and wool production, losses in weight and fertility, poor hide quality and an impairment of the host's immune system (McKelvie et al., 1993 and Otranto et al., 2004). Myiasis remains a neglected disease in spite of the heavy economic losses to the livestock industry (Otranto and Stevens, 2002). However, study on occurrence of myiasis in cattle and goats with respect to age, sex, breed and season is very scanty in Bangladesh. There is indeed a need to investigate the prevalence and incidence of animal myiasis to clarify the spread of infestation. The study was, therefore, undertaken to observe the occurrence of myiasis based on species, age, sex, breed, season and predilection sites in ruminants brought to Veterinary clinic, Bangladesh Agricultural University, Mymensingh.

\section{METHODOLOGY}

The study was conducted at Veterinary Clinic, Bangladesh Agricultural University, Mymensingh. Clinical data on maggot infestation in cattle and goat presented to Vet clinics from 2008 to December 2012, were recorded and analyzed to investigate the occurrence of myiasis with respect to species, age, sex, breed, season and predilection site. All animals were allotted into three groups according of ages i.e. $<6$ months, 6 months to 2 years and $>2$ years. Moreover, data were categorized as male and female according to sex. To consider the relation between breed and affection of maggot, data were also categorized as local and cross. To study the relationship between maggot infestation and time of the year as season data were distributed into three parts, i.e. March to June, July to October and November to February. Descriptive statistical analysis was performed to get results and all data presented as percentage.

\section{RESULTS AND DISCUSSION}

A retrospective study was performed to observe the occurrence of maggot wounds in ruminants and to investigate the relation among maggot infestation and different factors such as age, sex, breed, season etc. Predilection sites of maggot in affected animals were also considered.

Occurrence of myiasis from 2008 to 2012 is presented in Fig. 1. Results showed that total 151 ruminants were affected with myiasis among which $16.6 \%$ animals were affected in 2008, $18.5 \%$ in $2009,20.5 \%$ in $2010,22.5 \%$ in 2011 and $21.9 \%$ animals in 2012 . The occurrence was increasing year by year. Papadopoulos et al. (1997) reported that the prevalence of myiasis could be $37.4 \%$, which might go up to $100 \%$. Animal population infestated during the study period are shown in Fig. 2 . We found that 32\% calve, 17\% heifers, $8 \%$ oxen, $19 \%$ cows and $24 \%$ goats were affected in $2008 ; 34 \%$ calves, $13 \%$ heifers, $9 \%$ oxen, $15 \%$ cows and $29 \%$ goats in $2009 ; 29 \%$ calves, $11 \%$ heifers, $11 \%$ oxen, $7 \%$ cows and $34 \%$ goats in $2010 ; 38 \%$ calves, $8 \%$ heifers, $5 \%$ oxen, $22 \%$ cows and $27 \%$ goats in $2011 ; 36 \%$ calves, $13 \%$ heifers, $6 \%$ oxen, $17 \%$ cows and $28 \%$ goats in 2012. Between two species, more affection was present in cattle (71.6\%.) (Fig. 3). Similarly, Sergio et al. (2007) have stated cattle as the most frequent hosts 
for myiasis and they have found $46.4 \%$ myiasis affection in cattle. In Bangladesh, cattle comprise as a major surgical patients and they sustain different types of wounds, which frequently become complicated with maggot infestation in the field condition (Rahman et al., 2009).

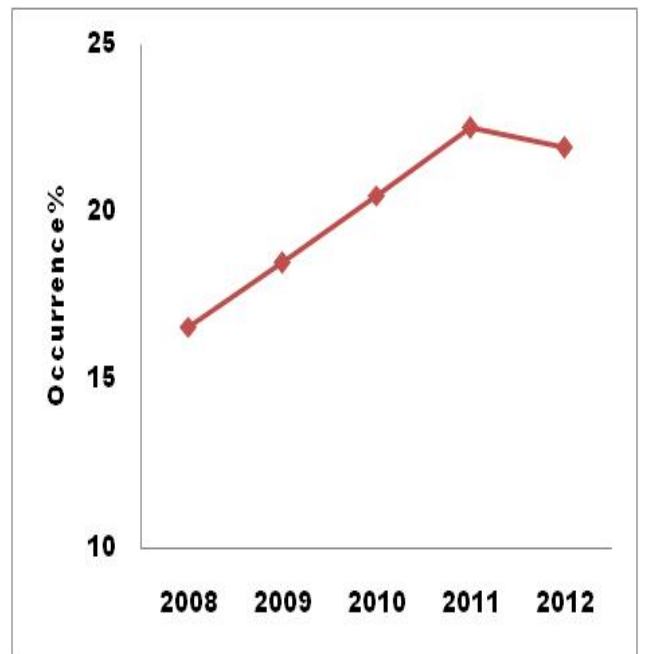

Fig. 1. Occurrence of myiasis during study

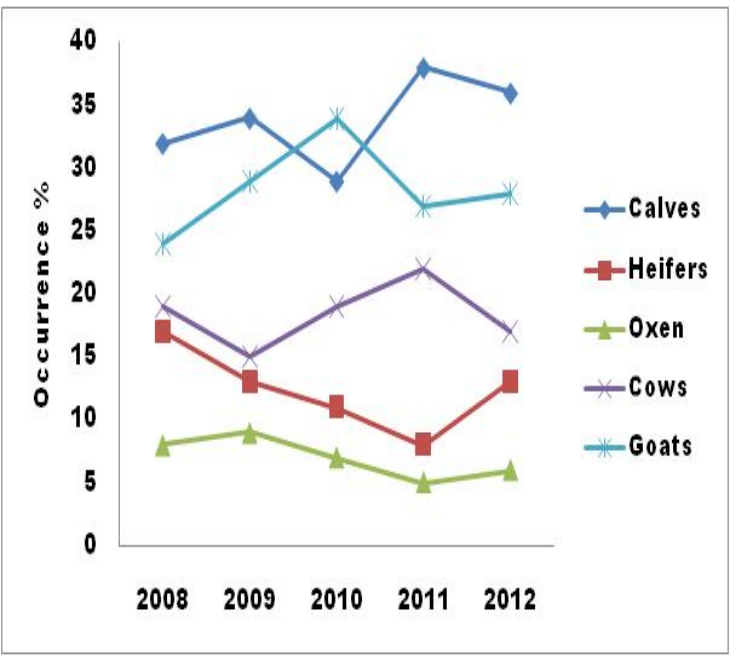

Fig. 2. Occurrence of myiasis in different population

We categorized data according to sex, age, breed, seasons and anatomical location of maggot wounds during the study. It was observed that the female animals $(66 \%)$ were more frequently affected than the males (34\%) (Fig. 4). Percentages of maggot infested animals in respect to age are shown in Fig. 5 . The occurrence of myiasis was higher $(41 \%)$ in animals of less than 6 months of age. This result is in contrast with the reports of Rahman et al. (2009) who investigated that the highest occurrence $(40 \%)$ was found in the adult animals of over 2 years and the lowest (27\%) occurrence was found in the calves of below 6 months. Moreover, among the affected animals, $57 \%$ were crossbred and $43 \%$ were local bred irrespective of sex and age (Fig. 6). This result corresponds well with the findings of Kara et al. (2005) and Rahman et al. (2009). They have stated that infestation rate of wounds with fly larvae was lower in the native cattle than that of crossbred. In addition, more affection was observed from March to June (80\%) (Fig. 7). This finding is in consistent with that of Alahmed (2004) and they stated higher incidences of myiasis during March-May (60\%) due to optimum temperature and relative humidity. He also reported lower infestation during dry hot season (June-August, 5\%) and cold season (December-February, 1.5\%), as observed in the study during July-October (13\%) and November-February (7\%) (Fig. 7). Flies responsible for the condition prefer a warm and humid environment. Therefore, myiasis is limited to the summer months in temperate zones, but may occur all the year round in the tropics (Maier and Honigsmann, 2004; Marty and Whiteside, 2005). However, Temperature and relative humidity are conducive in controlling myiasis. 


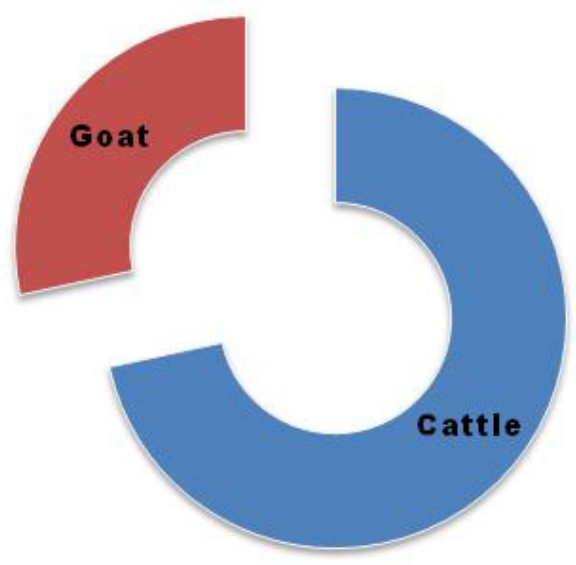

Fig. 3. Myiasis occured in two species

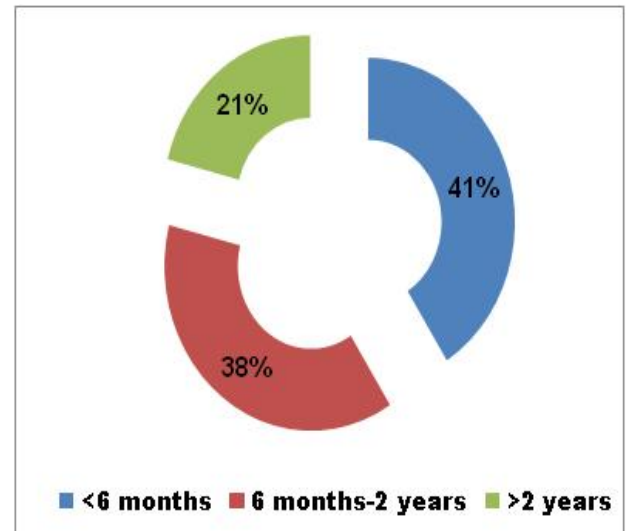

Fig. 5. Occurrence of myiasis in three age groups

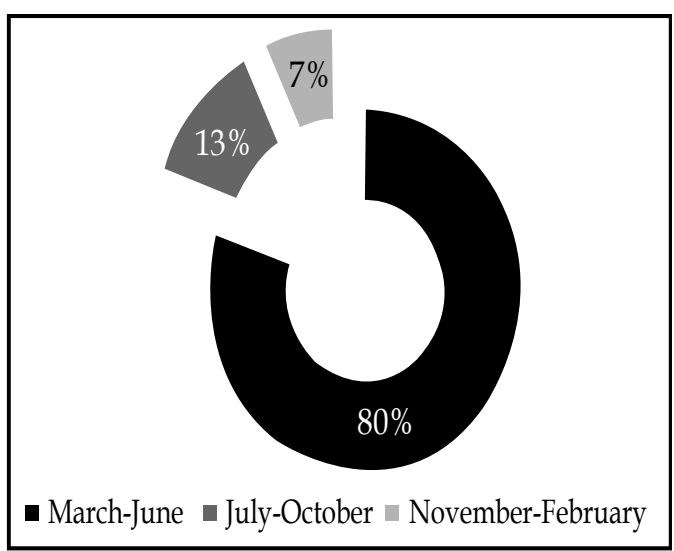

Fig. 7. Myiasis occured in different seasons

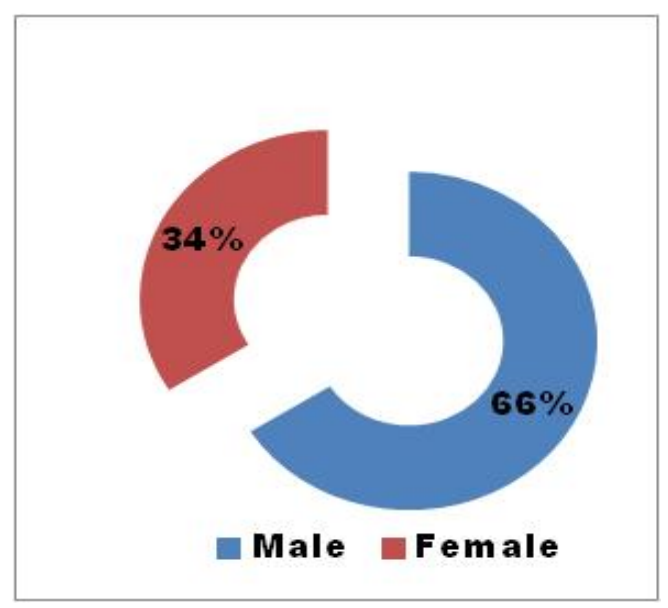

Fig. 4. Occurrence of myiasis in respect to sex

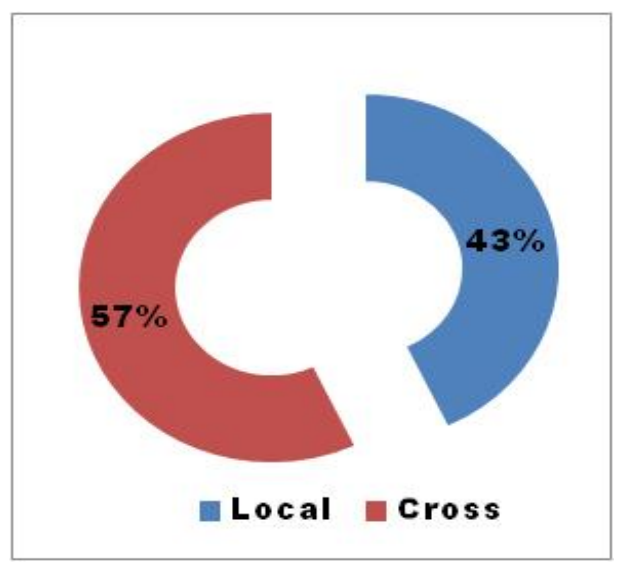

Fig. 6. Breeds affected with myiasis

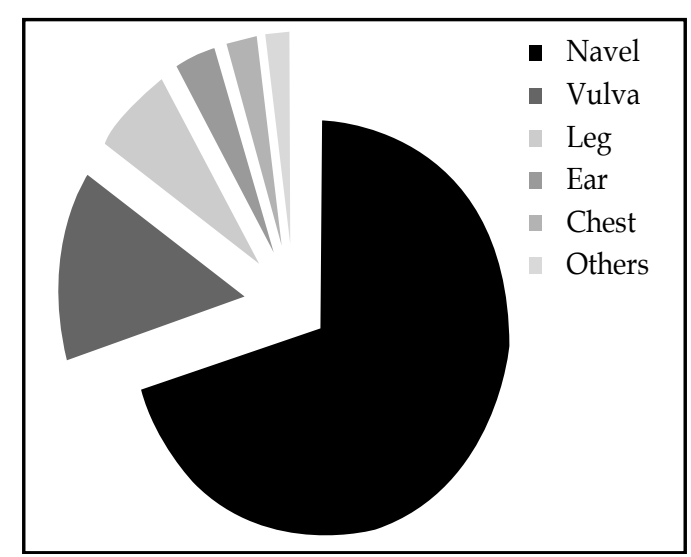

Fig. 8. Myiasis occured in anatomical locations 

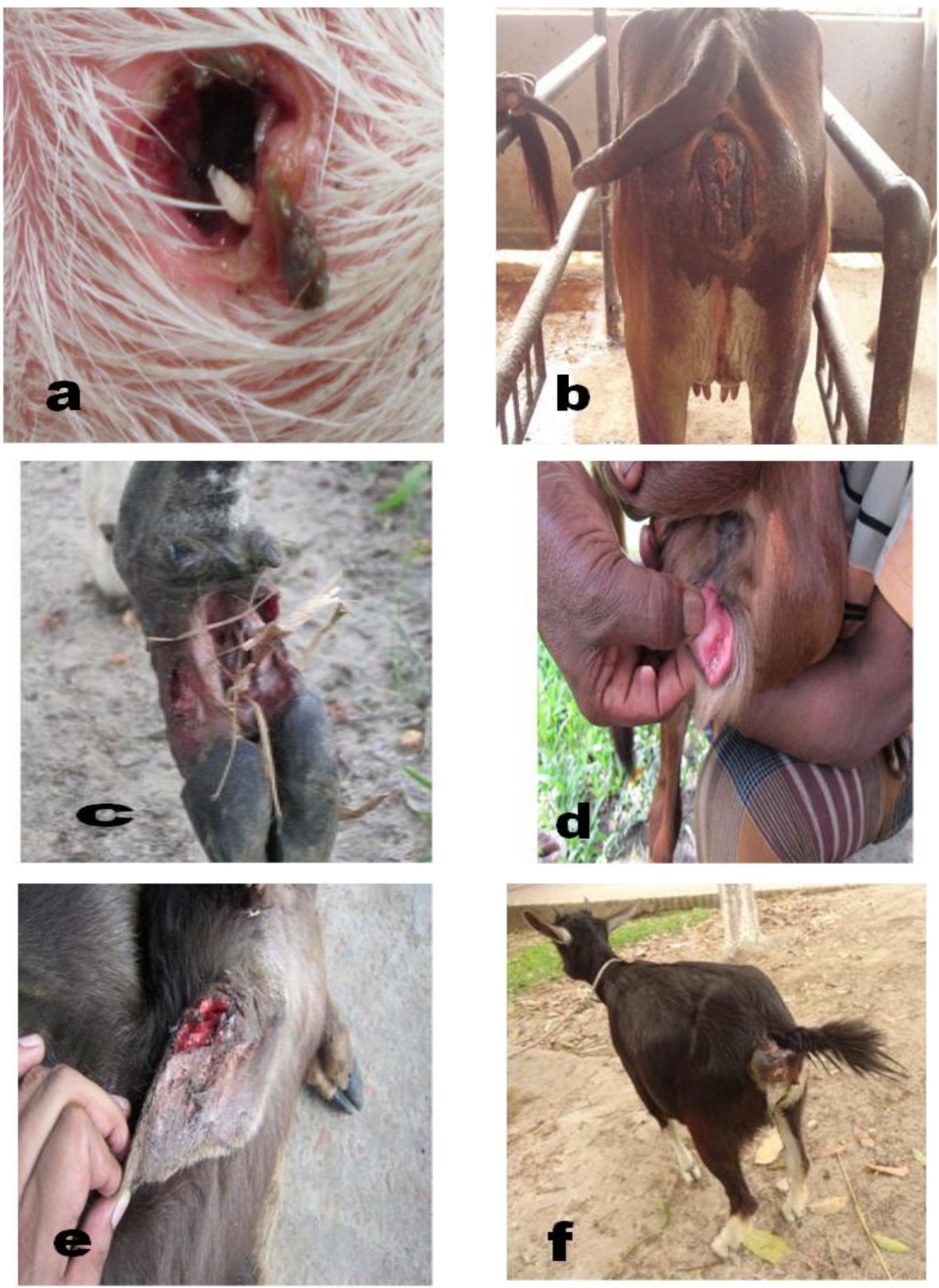

Fig. 9 Represents occurrence of myiasis in naval (a), vulva of cow (b), leg (c), vulva of calf (d), ear (e) and vulva of she goat (f) 


\section{CONCLUSIONS}

The infestation results in emaciation, malaise, and reduces fitness and efficiency of animals. Some of the wounds become so severe that euthanasia may be recommended. Wounds or any breach in the continuation in the skin may result in maggot infestation. Indeed, removal of the larvae allows more rapid healing. With respect to prevention, veterinarians and farmers should be aware about the effectiveness of treating all skin wounds. Preventive measures should be undertaken to minimize losses from myiasis. Dissemination of these findings among the farmers may prevent maggot infestation and control the spread of myiasis.

\section{REFERENCES}

Alahmed, A. M. 2004. Myiasis in sheep farms in Riyadh Region, Saudi Arabia. Journal of the Egyptian Society of Parasitology, 34(1): 153-160.

Chhabra, M. B. and Pathak, K. M. L. 2009. Myiasis of domestic animals and man in India. Journal of Veterinary Parasitology, 23(1): 1-7.

Kara, M., Arslan, M. O. and Gicik, Y. 2005. The prevalence of bovine hypodermosis in Kars province, Turkey. Tropical Animal Health and Production, 37(8): 617-622.

Maier, H. and Honigsmann, H. 2004. Furuncular myiasis caused by Dermatobia hominis, the human botfly. Journal of American Academy of Dermatology, 50: 26-30.

Marty, F. M. and Whiteside, K. R. 2005. Myiasis due to Dermatobia Hominis (Human Botfly). North England Journal of Medicine, 352-361.

McKelvie, L., Hamal, K. and Reynolds, R. 1993. Producer and consumer welfare effects of an invasion of screwworm fly in the Australian livestock sector. A BARE report to the Queensland Department of Primary Industries, Brisbane, Australia.

Obanda, V., Ndambiri, E. M., Kingori, E., Gakuya, F., Lwande, O. W. and Alasaad, S. 2013.Traumatic myiasis in free-ranging eland, reported from Kenya. Parasites $\mathcal{E}$ Vectors, 6: 89.

Otranto, D., and Stevens, J.R. 2002. Molecular approaches to the study of myiasis-causing larvae. Internation Journal of Parasitology, 32: 1345-1360.

Otranto, D., Traversa, D. and Giangaspero, A. 2004. Myiasis caused by Oestridae: serological and molecular diagnosis. Parasitologia, 46(1-2): 169-172.

Papadopoulos, E., Himonas, C. and Boulard, C. 1997. The prevalence of bovine hypodermosis in Greece. Parasitologia, 39(4): 431-433.

Rahman, M. A., Hossen, M. A. and Alam, M. R. 2009. Clinical Evaluation of Different Treatment Regimes for Management of Myiasis in Cattle. Bangladesh Journal of Veterinary Medicine, 7(2): 348-352.

Sergio, E. B., José, D. E., Angel, B. C., Franklin, C., Janina, S., Sabina, B. and Enrique, M. 2007. Incidence of myiasis in Panama during the eradication of Cochliomyia hominivorax. Sección de Entomología Médica, Instituto Conmemorativo Gorgas de Estudios de la Salud, PO Box 0816-02593, Panama.

Zumpt, F. 1965. Myiasis in Man and Animals in the Old World. London: Butterworths, pp. 267. 